\title{
The company as an active subject of environmental crime: A review
}

\section{Sérgio Luiz Silva Santos ${ }^{1}$, José Heder Benatti ${ }^{2}$, Elcemira Maria de Oliveira ${ }^{3}$}

\author{
1, 2,3Programa de Pós-Graduação em Ciência e Meio Ambiente (PPGMA) do Instituto de Ciências Exatas e Naturais (ICEN) da \\ Universidade Federal do Pará (UFPA). Avenida Augusto Correa 01. Campus Guamá. Belém-PA. Brasil. CEP: 66075-110.
}

Email: falcon67@uol.com.br

Received: September $11^{\text {th }}, 2017$

Accepted: September $25^{\text {th }}, 2017$

Published: September $30^{\text {th }}, 2017$

Copyright $\odot 2016$ by authors and Institute of Technology Galileo of Amazon (ITEGAM)

This work is licensed under the Creative Commons Attribution International

License (CC BY 4.0)

http://creativecommons.org/licenses/by/4.0/ (c) (i) (3) Open Acetes:

\begin{abstract}
The article aims to describe the environmental crime committed by a corporation in the environmental universe with a focus on criminality practiced through a company in the state of Amazonas, which was tried and convicted for committing an environmental crime under law number 9605/1998, Based on the law in epigraph the legal entity will practice environmental crime, such as air pollution, pollution of rivers, among other environmental crimes.

Keywords: Environmental Crime. Legal person. Environment.
\end{abstract}

\section{A empresa como sujeito ativo de crime ambiental: Uma Revisão}

\section{RESUMO}

O artigo visará descrever o crime ambiental praticado por uma corporação, no universo do meio ambiente com fulcro na criminalidade praticada por meio de uma empresa, no estado do Amazonas a qual foi julgada e condenada por praticar crime ambiental previsto na lei número 9.605/1998, com base na lei em epigrafe, a pessoa jurídica praticará crime ambiental, tais como a poluição do ar atmosférico, poluição dos rios, dentre outros crimes ambientais.

Palavras-chave: Crime Ambiental, Pessoa Jurídica, Meio Ambiente

\section{INTRODUÇÃO}

O Artigo 225, § $3^{\circ}$, da Constituição Federal de 1998 [1], norteia diversos princípios ambientais dentre os quais: Princípio da Supremacia do Interesse Público; Princípio do Direito Humano Fundamental; Princípio do Equilíbrio; Princípio do Limite; Princípio da Responsabilidade; Princípio do Desenvolvimento Sustentável; Princípio da Educação Ambiental; Princípio da Supremacia do Interesse Público; Princípio da Indisponibilidade do Interesse Público; Princípio da Proteção Ambiental; Princípio da Prevenção ou Precaução; Princípio Poluidor Pagador; Princípio da Obrigatoriedade da Avaliação Prévia em Obras Potencialmente Danosa ao Meio Ambiente; Princípio da Publicidade; Princípio da Participação; Princípio da Informação; Principio da Função Social Ambiental da Propriedade, [2][3]. Esse inovador artigo constitucional teve inspiração na Conferência do Ambiente Humano, Estocolmo, Suécia, 1972.

A sustentabilidade e preservação ambiental prevista na Carta Magna insculpiram no Artigo $225 \S 3^{\circ}$ as bases para a elaboração da Lei 9.605/1998 - Lei dos crimes ambientais [4] deixando claro a possibilidade da pessoa jurídica cometer e ser apenada pela pratica de crimes ambientais. Claro está que a finalidade maior da Constituição Federal é trazer efetividade e utilidade para o direito criminal ambiental bem como para o direito penal ambiental estabelecendo sanções penais concretas $[5]$.

A Lei $n^{\circ} 9.605$ de 13 de fevereiro de 1988 instrumentalizou e regulamentou o preceito constitucional da criminalização da pessoa jurídica, prevendo no artigo $3^{\circ} \mathrm{e}$ parágrafo único, a responsabilização criminal do ente coletivo, havendo a possibilidade da aplicação do concurso de pessoas aos coautores e partícipes, que juntamente com uma empresa praticar crime ambiental. Há também na lei criminal ambiental a possibilidade da desconsideração da personalidade jurídica, que é um instituto eminentemente cível, previsto no artigo $4^{\circ}$, da lei em epígrafe. $\mathrm{Na}$ reparação do dano ambiental pode o juiz decretar a desconsideração da personalidade jurídica alcançando os bens dos sócios, das pessoas físicas sempre que a personalidade jurídica causar dificuldade à reparação do dano. 


\section{REVISÃO BIBLIOGRÁFICA}

Nos dias atuais defende-se a ideia de desenvolvimento sustentável. É necessária a definição do que seja desenvolvimento sustentável, a terminologia foi criada na Conferência Mundial do Meio Ambiente, realizada em 1972 em Estocolmo - capital da Suécia, significa um desenvolvimento que responde às necessidades do presente sem comprometer a capacidade das gerações futuras de responder às suas próprias necessidades.

A utilização dos princípios do desenvolvimento sustentável na utilização dos recursos naturais, como uma forma de balancear a necessidade do ser humano de um desenvolvimento sustentável com a exploração do meio ambiente de maneira a não esgotar os recursos ambientais.

A matéria do Direito Ambiental propriamente dita consta no Capítulo VI, dentro do Título VIII, da Ordem Social. Este capítulo como bem ressalva é um dos mais importantes e modernos capítulos da Constituição Federal de 1988, [6].

$\mathrm{O}$ artigo 174 parágrafo $3^{\circ}$ determina que o Estado favoreça a organização da atividade garimpeira em cooperativas, levando em conta a proteção do meio ambiente, além de promoção econômico-social dos garimpeiros, quer dizer que, se o ambiente não estiver devidamente protegido, o Estado não poderá favorecer a organização da atividade garimpeira.

No artigo 186, parágrafo $2^{\circ}$ fica estabelecido que a propriedade rural só cumpra sua função social quando fizer a utilização adequada dos recursos naturais disponíveis e a preservação do meio ambiente.

O artigo 220, parágrafo $3^{\circ}$, inciso II, traz referência relevante, quando determina que compete à lei federal estabelecer meios legais que garantam às pessoas e à família, a possibilidade de se defenderem da propaganda de produtos, práticas e serviços que possam ser nocivas à saúde e ao meio ambiente.

O Direito Ambiental brasileiro toma vida autônoma com a promulgação da Constituição Federal de 1988, previsto no artigo 225 , impondo ao poder público e à coletividade sua preservação para as presentes e futuras gerações, prevendo ainda medidas assecuratórias para sua efetividade, impondo de forma implícita o desenvolvimento sustentável. Art. 225. Todos têm, direito ao meio ambiente ecologicamente equilibrado, bem de uso comum do povo e essencial à sadia qualidade de vida, impondo-se ao Poder Público e à coletividade o dever de defendê-lo e preserválo para os presentes e futuras gerações.

O parágrafo $1^{\circ}$, do arrolado artigo 225 , da Constituição Federal de 1988 descreve as medidas e as providências que incumbem ao Poder Publico para se assegurar à efetividade do direito: Parágrafo $1^{\circ}$ - Para assegurar a efetividade desse direito, incumbe ao Poder Público: I - preservar e restaurar os processos ecológicos essenciais e prover o manejo ecológico das espécies e ecossistemas; II- preservar a diversidade e a integridade do patrimônio genético do País e fiscalizar as entidades dedicadas à pesquisa e manipulação de material genético; III- Definir, em todas as unidades da Federação, espaços territoriais e seus componentes a serem especialmente protegidos, sendo a alteração e a supressão permitidas somente através de lei, vedada qualquer utilização que comprometa a integridade dos atributos que justifiquem sua proteção; IV - exigir, na forma da lei, para instalação de obra ou atividade potencialmente causadora de significativa degradação do meio ambiente, estudo prévio de impacto ambiental, a que se dará publicidade; V- Controlar a produção, a comercialização e o emprego de técnicas, métodos e substancias que comportem risco para a vida, a qualidade de vida e o meio ambiente; VI- Promover a educação ambiental em todos os níveis de ensino e a conscientização pública para a preservação do meio ambiente; VII- Proteger a fauna e a flora, vedadas, na forma da lei, as práticas que coloquem em risco sua função ecológica, provoquem a extinção de espécies ou submetam os animais à crueldade.

Além destes meios de atuação do Poder Público previsto em nossa Constituição Federal outras condutas preservacionistas poderão ser utilizadas para evitar geração de danos ao meio ambiente.

A atividade mineradora deverá ser reparada, quando houver dano ambiental, como preleciona a Constituição Federal de 1988, artigo $225, \S \S 2^{\circ}$ e $6^{\circ}: \S 2^{\circ}$ Aquele que explorar recursos minerais fica obrigado a recuperar o meio ambiente degradado, de acordo com solução técnica exigida pelo órgão público competente, na forma da lei; $\S 6^{\circ}$ As usinas que operem com reator nuclear deverão ter sua localização definida em lei federal, sem o que não poderão ser instaladas.

Cabe aqui ressaltar outro dispositivo constitucional, qual seja o artigo 173 parágrafo $5^{\circ}$, onde prevê a possibilidade de se responsabilizar as pessoas jurídicas, independentemente da responsabilidade de seus representantes ou de seus dirigentes por atos praticados.

Art. 173. Ressalvados os casos previstos nesta Constituição, a exploração direta de atividade econômica pelo Estado só será permitida quando necessária aos imperativos da segurança nacional ou a relevante interesse coletivo, conforme definidos em lei.

$\S 5^{\circ} \mathrm{A}$ lei, sem prejuízo da responsabilidade individual dos dirigentes da pessoa jurídica, estabelecerá a responsabilidade desta, sujeitando-a às punições compatíveis com sua natureza, nos atos praticados contra a ordem econômica e financeira e contra a economia popular.

$\mathrm{O}$ artigo 225, parágrafo $4^{\circ}$, declara como "patrimônio nacional": A Floresta Amazônica; A Mata Atlântica; A Serra do Mar; O Pantanal Mato-Grossense; A Zona Costeira.

A constituição Federal de 1988 não teve a intenção de tornar as áreas ambientais imitáveis, mas utilizadas de forma sustentável.

Este preceito de proteção difusa do meio ambiente, é mais avançado do que àquelas Constituições até então existentes, em outros países, que adotam a preservação ambiental no texto constitucional.

No artigo 31 parágrafo $3^{\circ}$, inciso II, traz referência relevante às terras ocupadas pelos índios imprescindíveis à preservação dos recursos ambientais necessários a seu bem estar.

Modernamente a doutrina majoritária brasileira adota o conceito analítico de crime, com a adoção da Teoria Tripartida do crime, que assim define o crime como fato típico antijurídico e culpável, aplicável também aos crimes ambientais praticados por pessoa jurídica, entende: A função do conceito analítico de crime é a de analisar todos os elementos ou características que integram o conceito de infração penal sem que com isso se queira fragmentá-lo. O crime é, certamente, um todo unitário e indivisível. Ou o agente comete o delito (fato típico, ilícito e culpável) ou o fato por ele praticado será considerado um indiferente penal. $\mathrm{O}$ estudo estratificado ou analítico permitenos, com clareza, verificar a existência ou não da infração penal; daí a sua importância [7].

O crime é divido em três partes fundamentais, conforme a teoria do crime, tendo como partes integrantes a tipicidade, antijuridicidade e culpabilidade. Tipicidade é o fato típico, previsto em lei, derivada da conduta humana ou da empresa, no tocante à criminalidade ambiental praticada por pessoa jurídica, 
positiva ou negativa que resulta em infração penal. Antijuridicidade é a conduta em desacordo com o dispositivo criminal. Culpabilidade é a censura do ordenamento jurídico a um caso concreto que seja típico e também antijurídico.

A realidade dos crimes econômicos e ambientais relativos às pessoas jurídicas trouxe a discussão mundial sobre a necessidade de sua responsabilização penal [8].

Em princípio só seria possível a aplicação de penalização criminal ambiental à pessoa jurídica, caso também se imputasse pena ao seu responsável legal era o que entendia a doutrina e a jurisprudência até então, aplicando-se em consequência a Teoria da Dupla Imputação, que preconizava a imposição de pena ao ente coletivo e também ao responsável direto pelo ato causador do crime ambiental simultaneamente. A pessoa jurídica jamais poderia figurar no polo passivo de uma ação penal ambiental sozinho, a criminalização de seu representante legal causador do delito ambiental se fazia necessário, segundo o entendimento da Teoria da Dupla Imputação. Penalizava-se o ente coletivo e em concurso necessário de pessoas também o seu representante legal, à semelhança do previsto no artigo $29, \S \S 1^{\circ}$ e $2^{\circ}$, do Código Penal [9].

Art. 29 - Quem, de qualquer modo, concorre para o crime incide nas penas a este cominadas, na medida de sua culpabilidade. $\S 1^{\circ}$ - Se a participação for de menor importância, a pena pode ser diminuída de um sexto a um terço. (Redação dada pela Lei ${ }^{\circ} 7.209$, de 11.7.1984)

$\S 2^{\circ}$ - Se algum dos concorrentes quis participar de crime menos grave, ser-lhe-á aplicada a pena deste; essa pena será aumentada até metade, na hipótese de ter sido previsível o resultado mais grave.

As empresas possuem sanções específicas levando-se em consideração o seu caráter diferenciado previsão expressa dos artigos: 18, 21, 22 e 23, da Lei $n^{\circ}$ 9.605/1998, que tem como cominação: multa, restrição de direitos e prestação de serviços à comunidade. A aplicação da pena à empresa, no universo do meio ambiente se pautará na gravidade da infração e aos antecedentes do infrator é o que preceitua o artigo $6^{\circ}$, incisos I, II e III, da lei de reprimenda aos crimes ambientais. Fica, portanto patente o concurso de pessoas, na modalidade comissiva e omissiva subdividindo-se ainda em omissivo próprio e impróprio.

Nos delitos omissivos não há coautoria ou participação mediante omissão as contribuições individuais completam num todo unitário, devendo o resultado final ser imputado a todos os participantes [10][11]. É impossível, portanto, o concurso de pessoas em crimes omissivos.

O meio ambiente é o conjunto de condições naturais em determinada região ou globalmente, em todo o planeta, e da influência delas decorrentes que, atuando sobre os organismos vivos e os seres humanos, condicionam sua preservação, saúde e bem-estar à luz das leis, influências e interações de ordem física, química e biológica, que permite, abriga e rege a vida em todas as suas formas, dessa forma o crime ambiental está inserido dentro da disciplina meio ambiente, que é sinônimo da matéria direito ambiental, como bem disciplina a doutrina e a legislação nacional e estrangeira.

A palavra "ambiente" vem do Latim ambiens, que significa algo que o cerca ou envolve os corpos por todos os lados, ou seja, em outras palavras significa a esfera ou o circulo em que vivemos.

No conceito de meio ambiente, estão incluídos tantos os elementos vivos ou não da natureza, como também aqueles que abarcam qualquer tipo de vida, o que inclui espaços artificiais, criados pelo homem.

"Meio Ambiente é o espaço ocupado pelos seres vivos, onde habitam e há interação recíproca, influenciando na forma de vida e na mantença desse lugar, com todas as suas naturais características" [12].

A Lei 6.938 de 1981, Lei da política nacional do meio ambiente define com precisão o que seja meio ambiente, no artigo $3^{\circ}$, incisos e alíneas: Art $3^{\circ}$ - Para os fins previstos nesta Lei, entende-se por:

I - meio ambiente, o conjunto de condições, leis, influências e interações de ordem física, química e biológica, que permite, abriga e rege a vida em todas as suas formas;

II - degradação da qualidade ambiental, a alteração adversa das características do meio ambiente;

III - poluição, a degradação da qualidade ambiental resultante de atividades que direta ou indiretamente: população;

a) prejudiquem a saúde, a segurança e o bem-estar da

b) criem condições adversas às atividades sociais e econômicas;

c) afetem desfavoravelmente a biota;

d) afetem as condições estéticas ou sanitárias do meio ambiente;

e) lancem matérias ou energia em desacordo com os padrões ambientais estabelecidos;

IV - poluidor, a pessoa física ou jurídica, de direito público ou privado, responsável, direta ou indiretamente, por atividade causadora de degradação ambiental;

V - recursos ambientais, a atmosfera, as águas interiores, superficiais e subterrâneas, os estuários, o mar territorial, o solo, o subsolo e os elementos da biosfera.

V - recursos ambientais: a atmosfera, as águas interiores, superficiais e subterrâneas, os estuários, o mar territorial, o solo, o subsolo, os elementos da biosfera, a fauna e a flora, [14].

Como bem se pode notar, a terminologia "ambiente", é ampla e pode abrigar inúmeras realidades que se encontram no interior da legislação ambiental. Com o passar dos anos foi se entendendo que o termo citado era dotado de uma abrangência bem maior. Meio ambiente nada mais é do que a expressão do patrimônio natural e suas relações com o ser vivo [15].

A doutrina nacional, assim como os dispositivos legas usam o termo "meio ambiente", como nota-se do artigo 225 da Carta Magna brasileira, as leis extravagantes como a da política nacional do meio ambiente, Lei $\mathrm{n}^{\circ}$ 6.938/1981, também faz uso das palavras compostas meio ambiente. Os doutrinadores nacionais e estrangeiros utilizam-se da expressão "Direito Ambiental" daí concluir-se que os termos são sinônimos, não havendo dicotomia entre eles.

O Superior Tribunal de Justiça - STJ entendia só ser possível a criminalização da pessoa jurídica, quando também condenado fosse à pessoa física, representante legal ou contratual, entendimento preconizado no julgamento STJ recurso em habeas corpus $n^{\circ} 19.734$ - RO (2006/0131414-7) relator: Ministro Gilson Dipp - Julgamento: 23 de setembro 2006 - publicação: DJ 23/10/2006; STJ - habeas corpus $\mathrm{n}^{\circ}$ 86.259 - MG (2007/0154492-9) - relator: Ministro Napoleão Nunes Maia - julgamento: 10 de junho de 2008 - publicação: DJ 18/06/2008, 4026257; STJ - recurso especial no 800.817 Relator: Ministro Celso Limogi (Desebargador convocado do TJ/SP - julgado: 04 de fevereiro de 2010 - publicação: dje 22/2/2010; STJ - Recurso em habras corpus $n^{\circ} 24.239$ - ES 
(2008/0169113-5) - relator: Ministro OG Fernandes julgamento: 10 de junho de 2010 - publicação: dj: 01/07/2010.

No final do ano de 2011, no mês de setembro surge uma nova posição defendida pelo Ministro Dias Toffoli, do STF Supremo Tribunal Federal, que afirmava textualmente ser possível a penalização criminal nos delitos cometidos contra o meio ambiente, pelo ente coletivo, mesmo que o seu responsável legal fosse absolvido. STF - RECURSO EXTRAORDINÁRIO RE No 628582 RS - RELATOR: MINISTRO DIAS TOFFOLI JULGAMENTO: 22 DE FEVEREIRO DE 2011 PUBLICAÇÃO: DJE 03/03/ 2011.

A Teoria da Dupla Imputação estaria, por conseguinte superada, para fazer valer os ditames Constitucionais previstos o artigo $225, \S 3^{\circ}$ e artigo $3^{\circ}$, parágrafo único da Lei no $9.605 / 1998$, não fazendo nenhuma ressalva quanto à simultaneidade do ente coletivo e seu representante legal para serem penalizados criminalmente terem que compulsoriamente participar de concurso de pessoas, quando da praticar de crimes contra o meio ambiente.

Com a nova decisão do Ministro Dias Toffoli, do Supremo Tribunal Federal - STF, a Teoria que mais se aproximaria no tocante a criminalização do ente coletivo seria a Teoria do Domínio do Fato, pois a pessoa jurídica tem personalidade distinta da do seu representante legal, atuando com domínio final de suas ações, podendo no caso concreto a pessoa jurídica para ser penalizada criminalmente por delitos cometidos contra o meio ambiente independente da condenação de seu representante legal. Justifica-se pela oportunidade dos momentos objetivos e subjetivos se cingirem, portanto o novo entendimento em casos concretos não deixa dúvida quanto à aplicabilidade e a adoção da Teoria do Domínio do Fato aos delitos cometidos por pessoa jurídica contra o meio ambiente. Resolveria, por conseguinte o problema do concurso de pessoas, mas especificamente no tocante a coautoria nos crimes cometidos contra o meio ambiente, mas abre outra cisão, pois a Teoria do Domínio do Fato é incompatível com o instituto dos crimes omissivos, afastada, portanto estaria sua aplicabilidade nesse quesito, no tocante à omissão, pois não há como coadunar institutos diametralmente inconciliáveis.

A constituição Federal não confere só ao cidadão individualmente, bem jurídico, de natureza ambiental e direito subjetivo público, mas também é um direito difuso, coletivo e individual homogêneo quando se refere ao meio ambiente, bem coletivo que deve ser ecologicamente equilibrado.

$\mathrm{O}$ ente coletivo à luz do Direito Internacional Público como sujeito ativo da penalização criminal ambiental, existe uma pluralidade reduzida de estados membros da Organização das Nações Unidas - ONU, que adotam a criminalização da pessoa jurídica como sujeito ativo de crime ambiental, dentre os quais estão países desenvolvidos do continente Europeu, América do Norte, América Latina e Ásia, os principais são: Alemanha, França, Holanda, Inglaterra, Dinamarca, Escócia, Espanha, Portugal, Estados Unidos, Canadá, França, Áustria, Noruega, Venezuela, Cuba e Japão.

\section{MATERIAIS E MÉTODOS}

O presente artigo embasou-se no método de abordagem Hipotético-Dedutivo, quanto à abordagem por trazer um entrelaçamento, uma união entre os métodos indutivos e o dedutivo, pois traz uma racionalização do método dedutivo e a experimentação do método indutivo. $\mathrm{O}$ método indutivo é o que representa a generalização, inicia-se do particular para uma questão mais ampla, em termos de fatos concretos, enquanto o método dedutivo opõe-se ao indutivo, pois parte de uma premissa geral para uma particularização. No tocante à natureza foi utilizado o método qualitativo. Quanto ao objetivo a metodologia utilizada foi a exploratória, por permitir uma sondagem familiar. No que diz respeito à análise teórica, o método empregado foi a análise teórico empírica. A metodologia de procedimento utilizado foi o bibliográfico, como principal, com análise teórico-empírica, interpretativa de dados primários em torno do tema, e também com apoio complementar em material disponível na rede mundial de computadores, por sugerir ao pesquisador captar as perspectivas e interpretações diretamente da fonte utilizando-se de bibliografia especializada no tocante ao objeto para a elaboração do artigo, sendo, portanto a predominante, enquanto as demais: legislação, Jurisprudência e doutrina foram complementares.

\section{RESULTADOS E DISCUSSÕES}

O tema referente à responsabilização penal de uma empresa, pessoa jurídica veio inovar o nosso arcabouço jurídico penal, que encontra suporte na doutrina e na jurisprudência pátria sob vários aspectos.

Entretanto, somente em 1998 veio a lume a Lei ${ }^{\circ} 9.605$ que estabeleceu as sanções penais e administrativas, regulamentando a Constituição federal de 1988.

A partir de então, com os poderes atribuídos ao Ministério Publico, pela própria Constituição Federal e depois, pela Constituição Federal e depois pelo Código de Defesa do Consumidor, somado- se à atividade dos órgãos ambientais, começa a haver a efetividade desta lei, passando especialmente as empresas a correr sérios riscos ao não observarem as regras ambientais, podendo sofrer severas e pesadas penas, tanto administrativas, civis e penais, que vão desde a interrupção das atividades, suspensão de direitos, tais como, não participar de licitações, não recebimento de incentivos fiscais e ou financiamentos oficiais, ou ainda, trabalhos comunitários, à prisão de todos que colaboraram para o delito, dirigentes ou não, além de multa, independentemente do dever de reparar os danos. Foi o que aconteceu com a empresa A. Gurgel do Carmo e Cia Ltda, que foi condenada pela prática de crimes ambientais, previsto na Lei 9.605 de 1988, além de sofrer sanções, cíveis e administrativas, inclusive sua condenação foi confirmada em segunda instância, ou seja, sua condenação foi confirmada pelo Tribunal de Justiça do Estado do Amazonas, com isso ocorreu o trânsito em julgado, que ocorre quando as partes, no caso o Ministério Público, que é o dono da ação penal e a empresa, não tem mais possibilidade de recorrer, por ter ocorrido o exaurimento dos recursos ou pelo decurso de tempo.

\section{CONCLUSÃO}

Do exposto conclui-se que a pessoa jurídica comete e poderá ser apenada pela pratica de crimes contra o meio ambiente. Existem nove teorias que tentam explicitam a existência da personalidade jurídica como sujeito ativo de crimes contra o meio ambiente, embora existam algumas que não admitem tal possibilidade, mas se debruçam sobre o tema expondo seus pontos de vistas. A principal e mais adotada é a Teoria da Ficção Jurídica de Savigny, referida Teoria embora muito utilizada, principalmente no Direito Penal, nega que o ente coletivo possa cometer crime e ser apenada: "Os entes coletivos ou pessoas jurídicas são criações artificiais do 
Direito, por uma ficção legal; isto é: o Direito trata as pessoas jurídicas (entes fictícios) como se fossem pessoas reais, atribuindo-lhes direitos e obrigações, por razões de ordem prática..." [15].

A Teoria da Realidade Ambientais é a que mais se aproxima da realidade dos crimes cometidos por pessoa jurídica contra o meio ambiente, afirmando que: As pessoas jurídicas não são meras abstrações ou ficções legais, mas entes reais, com capacidade e vontade próprias (com capacidade de ação) e, portanto, podem cometer crimes, (pois são realidades independentes das pessoas físicas que as compõem) e sofrer penas, [20].

$\mathrm{O}$ ente coletivo poderia responder criminalmente e integralmente por diversos outros crimes previstos no Código Penal, Legislações Penais e Processuais Penais Extravagantes, o rol atual é taxativo e restritivo, apenas crimes cometidos contra o meio ambiente, contra o consumidor e contra a ordem financeira e a economia popular poderão ser objeto de criminalização do ente coletivo, como é o caso dos delitos contra o meio ambiente. As sociedades empresarias cometem cada vez mais crimes de corrupção, tanto ativa quanto na modalidade passiva, sem contar os inúmeros crimes eleitorais, que são cometidos nas campanhas eleitorais, pelas pessoas jurídicas, portanto, facilmente poderiam ser objeto de criminalização.

A empresa A. Gurgel do Carmo e Cia Ltda foi condenada por ter cometido crime contra o meio ambiente, consistindo no desflorestamento e aterro de uma área de buritizal, que é considerada área de preservação permanente, no caso em tela a o magistrado entendeu que o responsável pelo empreendimento também havia cometido crime ambiental, condenando-os em concurso material, a luz do entendimento do Superior Tribunal de Justiça - STJ, que entende que condenada um ente societário, também será condenado o sócio, gerente, responsável pela empresa, adotando por conseguinte a Teoria do Domínio dos Fatos e a Teoria da Dupla Imputação, condena-se o ente coletivo e em concurso material, também o responsável pela empresa.

\section{AGRADECIMENTOS} (UFPA).

Ao PPGCMA do ICEN/Universidade Federal do Pará

\section{REFERÊNCIAS}

[1] BRASIL. A Constituição e o Supremo. Disponível em: http://www.stf.jus.br/arquivo/cms/publicacaoLegislacaoAnotada/ anexo/Completo.pdf. Acesso em: 23 março 2016.

[2] Miranda, Robinson Nicário de. Direito Ambiental. $3^{a}$ ed. São Paulo: Editora Rideel, 2011.

[3] Mukai, Toshio. Direito Ambiental Sistematizado. $4^{\mathrm{a}}$ ed. São Paulo: Forense Universitária, 2004.

[4] BRASIL. Lei número 9.605 de 12 de fevereiro de 1998. Dispõe sobre as sanções penais e administrativas derivadas de condutas e atividades lesivas ao meio ambiente, e dá outras providências.

[5] Fiorillo, Celso Antônio Pacheco. Curso de Direito Ambiental Brasileiro. São Paulo: Saraiva, 2006;

[6] Silva, José Afonso da. Direito Ambiental Constitucional. 5. ed. São Paulo: Malheiros, 2004.
[7] Greco, Rogério. Curso de Direito Penal - Parte Geral. $2^{\mathrm{a}}$ ed. Rio de Janeiro: Ediitora Impetus.

[8] Poggio Smanio, Giapaolo. Caderno Jurídico. Novas Formas de Criminalidade. São Paulo: Imprensa Oficial - SP. Escola Superior do Ministério Público de São Paulo. Ano I - $\mathbf{n}^{\mathbf{o}}$ 3 - outubro de 2001.

[9] Brasil. Decreto-lei número 2.848 de 07 de dezembro de 1940. Código Penal.

[10] Evangelista de Jesus, Damásio. Teoria do Domínio do fato no Concurso de Pessoas. ed. Saraiva, 1999.

[11] Revista Jurídica Escola Superior do Ministério Público São Paulo - Ano 1 - nº 2 - julho/dezembro de 2001.

[12] Nucci, Guilherme de Souza. Lei Penais e Processuais Penais Comentadas v. 2. $6^{\text {a }}$ Ed. São Paulo: Editora Revista dos Tribunais.

[14] BRASIL. Lei número 6.938 de 31 de agosto de 1981. Dispõe sobre a Política Nacional do Meio Ambiente, seus fins e mecanismos de formulação e aplicação, e dá outras providências.

[15] Constantino, Carlos Ernani. Delitos Ecológicos. $3^{\mathrm{a}}$ ed. Franca-SP: Lemos \& Cruz,2005.

[16] Direito Ambiental Contemporâneo. São Paulo: Saraiva, 2015.

[17] Franco, Alberto Silva; Stoco, Rui. Leis Penais Especiais e Sua Interpretação Jurisprudencial. V. 1. 7. Ed. São Paulo: Editora Revista dos Tribunais, 2001.

[18] Gomes; Maciel, Luiz Flávio; Silvio. Le supremo tribunal federal - STF - medida cautelar no habeas corpus - HC 88544 SP Disponível em https://stf.jusbrasil.com.br/jurisprudencia/14781172/medidacautelar-no- habeas-corpus-hc-88544-sp-stf; Acessado em $07-$ 06-2017.

[19] Ricardo Lewandowski - Julgamento: 27 de Abril de 2006 - Publicação: DJ 05/05/2006 - PP-00050 -. Acessado em 07-06-2017. Disponível https://stf.jusbrasil.com.br/jurisprudencia/14781172/medidacautelar-no- habeas-corpus-hc-88544-sp-stf; Acessado em 0706-2017.

[20] SUPERIOR TRIBUNAL DE JUSTIÇA - STJ - recurso em habeas corpus no 19.734 - RO (2006/0131414-7) relator: Ministro Gilson Dipp -Julgamento: 23 de setembro 2006 Publicação: DJ 23/10/2006. Visitado em 07-06-2017, Disponível em https://stj.jusbrasil.com.br/jurisprudencia/9054709/recursoordinario-em- habeas- corpus-rhc-19734-ro-2006-0131414-7stj/relatorio-e-voto-14233894\#.

[21] SUPERIOR TRIBUNAL DE JUSTIÇA - STJ - habeas corpus $n^{\circ} 86.259$ - MG (2007/0154492-9) - relator: Ministro Napoleão Nunes Maia - Julgamento: 10 de junho de 2008 DJ 4026257 - Publicação: 18/06/2008. Visitado em 07-06-2017; Crimes Ambientais - Comentários à Lei 9.605/1998. São Paulo: Editora Método, 2015. 